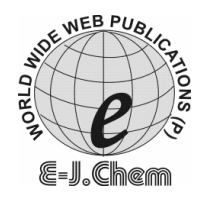

\title{
Liquid Chromatographic Method for Determination of Nisoldipine from Pharmaceutical Samples
}

\author{
AMIT GUPTA*, RAM S GAUD and S. GANGA \\ School of Pharmacy and Technology Management \\ SVKM's NMIMS University V. L. Mehta Road, \\ Vile Parle (W) Mumbai-56, India. \\ amitopgupta@gmail.com
}

Received 21 September 2009; Revised 25 November 2009; Accepted 10 January 2010

\begin{abstract}
A simple and specific high performance thin layer chromatographic method was developed and validated for the determination of nisoldipine from tablet dosage form. The method was carried out at $320 \mathrm{~nm}$ after extraction of drug in methanol. The method uses aluminum plates pre-coated with silica gel $60 \mathrm{~F}-254$ as stationary phase and cyclohexane-ethyl acetate-toluene $(3: 3: 4, \mathrm{v} / \mathrm{v} / \mathrm{v})$ as mobile phase. Linearity was established over a range of 400-2400 ng per zone. Both peak area ratio and peak height ratio showed acceptable correlation coefficient i.e. more than 0.99 . However we used peak area for validation purpose. Intra-day and inter-day precision was determined and found to have less than $6.0 \%$ RSD.
\end{abstract}

Keywords: HPTLC, Nisoldipine, Standard deviation, Relative standard deviation.

\section{Introduction}

Nisoldipine (NS) is chemically known as 3,5-pyridinedicarboxylic acid, 1,4-dihydro-2,6dimethyl-4-(2-nitrophenyl), methyl 2-methyl-propyl ester, $\mathrm{C}_{20} \mathrm{H}_{24} \mathrm{~N}_{2} \mathrm{O}_{6}$, a dihydropyridine calcium channel blocker (calcium ion antagonists or slow channel blockers) ${ }^{1}$. NS is a yellow crystalline substance, practically insoluble in water but soluble in ethanol. It has molecular weight of 388.4. It inhibits the transmembrane influx of calcium into vascular smooth muscle and cardiac muscle. NS is available as extended release tablets.

NS has been analyzed by various analytical methods including crystal structure elucidation ${ }^{2,3}$ and determination in formulations by $\mathrm{UV}^{4}$, voltametry ${ }^{5}$, polarography ${ }^{6}, \mathrm{TLC}^{7}$ and HPLC $^{8-11}$. Since NS has light sensitivity, its stability, kinetics of degradation and determination of impurities are reported by various techniques including $\mathrm{UV}^{12,13}$, polarography ${ }^{14}, \mathrm{HPLC}^{15,16}$ and $\mathrm{GC}^{17,18}$. Analysis of NS is also attempted for biological samples by HPLC ${ }^{19-22}$, GC $^{23}$ and LC-MS ${ }^{24,25}$. 
Determination of NS from available extended release tablet may involve criticality of unavoidable absorbance of polymers and hence absorption spectra of the NS may be interfered. Other methods like HPLC and GC involve long extraction procedures. Because of outstanding advantages of HPTLC ${ }^{26,27}$, it contributes to new applications ${ }^{28}$ since it separates out the polymers and excipients of formulation. In addition low cost, high sample throughput and rapid means of analysis gives added advantage ${ }^{29}$. Because of various advantages of HPTLC, it is considered as simple, rapid, accurate and precise technique and current work we have developed a quantitative method for determination of NS from extended release tablet formulation.

\section{Experimental}

Nisoldipine (NS) (99.15\% purity) was procured from Shandong Boyuan Chemical co, Ltd (Jinan, China), nifedipine was obtained from Wockhard Research Centre (Aurangabad, India). All solvents used were of analytical grades and were purchased from Merk (Worli, Mumbai, India).

\section{Standard solutions}

A stock solution of NS was prepared by dissolving $50 \mathrm{mg}$ of NS in $50 \mathrm{~mL}$ methanol. From the stock solution various standard solution containing NS (40 to $240 \mathrm{mg} \mathrm{mL}^{-1}$ ) were prepared by appropriate dilution of the stock solution with methanol.

\section{Test Sample solution}

Placebo blend compositing excipients as that of mentioned in available literature was prepared and known amount of the drug was added. It was dissolved into $20 \mathrm{~mL}$ of methanol. Samples were sonicated in bath sonicator for 10 minutes and filtered through whatman filter paper No 41. Sample was suitability diluted to $100 \mathrm{mg} \mathrm{mL}^{-1}$.

\section{Specificity}

To evaluate specificity of the method and interference by excipients, three samples were spotted i.e. (1) placebo, (2) NS standard sample with nifedipine and (3) NS standard sample, nifedipine extracted from placebo. Selection of nifedipine was done as an internal standard since it has similar physicochemical properties to that of NS.

\section{Linearity, precision and accuracy}

Linearity of the standard solution of NS from 400 to $2400 \mathrm{ng}$ per zone was evaluated by applying standard samples in triplicate. Also to find linearity for extraction procedure by spotting, samples were extracted in triplicate. The precision and accuracy of the method were evaluated by performing replicate analysis of standard sample of two concentrations i.e. 400 and $2400 \mathrm{ng}$ per zone against a calibration curve. Intra-day repeatability was determined by treating spiked placebo samples in six replicates on the same day for both concentrations. Inter-day repeatability was studied by comparing the results of assays performed on different days on the same spiked samples in six replicates.

The reproducibility of the method was checked by determining precision on a different analyst in a different laboratory. The precision was expressed in terms of intra-day and inter-day standard deviation (SD) and percentage relative standard deviation (RSD, \%), whereas accuracy was expressed as percent recovery (mean measured concentration/nominal concentration * 100).

\section{Limit of detection and limit of quantification}

To estimate the limit of detection (LOD) and limit of quantification (LOQ), test sample was done six times following the same mentioned earlier. The standard deviations $(\sigma)$ of the magnitude of measured area were calculated. The LOD was expressed as $3.3 * \sigma$ /slope of the calibration curve of the NS, whereas LOQ was expressed as $10 * \sigma$ /slope of the calibration curve of the same. 


\section{Recovery}

Extraction efficiency of the procedure was calculated by peak area of standard solution and that of spiked placebo solution. For this same, data obtained from linearity were processed.

\section{HPTLC analysis}

Chromatography was performed on $20 \mathrm{~cm} \times 10 \mathrm{~cm}$ aluminum plates coated with $250 \mu \mathrm{m}$ layers of silica gel $60 \mathrm{~F}_{254}$ (E. Merck, Germany). Sample and standard zones were applied to the plates as bands (number of tracks, 18, track distance from the left plate edges, $10 \mathrm{~mm}$, distance from plate bottom, $15 \mathrm{~mm}$, band length, $6 \mathrm{~mm}$, distance between bands, $10 \mathrm{~mm}$ from centers of bands) by means of an automatic TLC applicator AS 30 (Desaga, Heidelberg, Germany) which furnishes application of different volumes of the same standard and sample solutions as narrow bands which were detected as dark violet bands against a bright green background when viewed under $\mathrm{k}=254 \mathrm{~nm}$ light inside a UV cabinet (Desaga-UVIS) inside the scanner. Linear ascending development, with cyclohexan-ethyl acetate-toluene, $3: 3: 4(\mathrm{v} / \mathrm{v})$ as mobile phase was performed in a $20 \mathrm{~cm} \times 10 \mathrm{~cm}$ twin-trough glass chamber (Desaga), with tightly fitting lid, previously saturated with mobile phase vapour for $20 \mathrm{~min}$ at room temperature $\left(25 \pm 2{ }^{\circ} \mathrm{C}\right)$. The development distance was $8 \mathrm{~cm}$.

After development the plates were air dried. Densitometric scanning at $320 \mathrm{~nm}$ was then performed with a Densitometer CD 60 (Desaga) in absorbance mode operated by applicator AS30 software (Version 1.8.00). The source of radiation was a deuterium lamp emitting a continuous UV spectrum in the range $190-400 \mathrm{~nm}$.

\section{Results and Discussion}

\section{Linearity}

The linear regression data for the calibration curves in standard solutions and spiked placebo solutions are shown in Table 1. Under the earlier described conditions, NS was eluted at $\mathrm{R}_{\mathrm{f}}=0.36$ in both the matrices. Since peak area or peak can be taken for linearity, regression analysis of both parameters was done to find best suitable one. The peak area and peak height of NS varied linearly with concentration over the range used. The peak area $v s$. concentration for spiked placebo sample fitted well to a straight line, with the following equations for the calibration curves:

$$
y=0.6089 x+128.94 \text { and } y=0.4957 x+231.44 \text { for standard solutions. }
$$

The correlation coefficients $\left(\mathrm{R}^{2}\right)$ for both the calibration curves were in acceptable limit (more than 0.9900 ). However cause of higher $\mathrm{R}^{2}$ value, peak area was taken for further validation.

Table 1. Linearity and regression data.

\begin{tabular}{cccc}
\hline \multicolumn{2}{c}{ Linearity parameters } & Standard solutions & Spiked samples \\
\hline \multirow{2}{*}{ by peak } & range & $400-2400$ & $400-2400$ \\
area & equation of line & $0.4957 \mathrm{x}+231.44$ & $0.5413 \mathrm{x}+198.40$ \\
& correlation coefficient $\left(\mathrm{R}^{2}\right)$ & 0.992 & 0.9948 \\
\hline \multirow{2}{*}{ by peak } & range & $400-2400$ & $400-2400$ \\
area & equation of line & $0.1982 \mathrm{x}+118.98$ & $0.2154 \mathrm{x}+84.15$ \\
& correlation coefficient $\left(\mathrm{R}^{2}\right)$ & 0.9888 & 0.9941 \\
\hline
\end{tabular}

\section{Specificity}

To represent the specificity of the method for NS and possibility of any hindrance by excipients or internal standard, drug spiked sample and NS solution with internal standard (Nifedipine) were taken which is shown in Figure 1. 


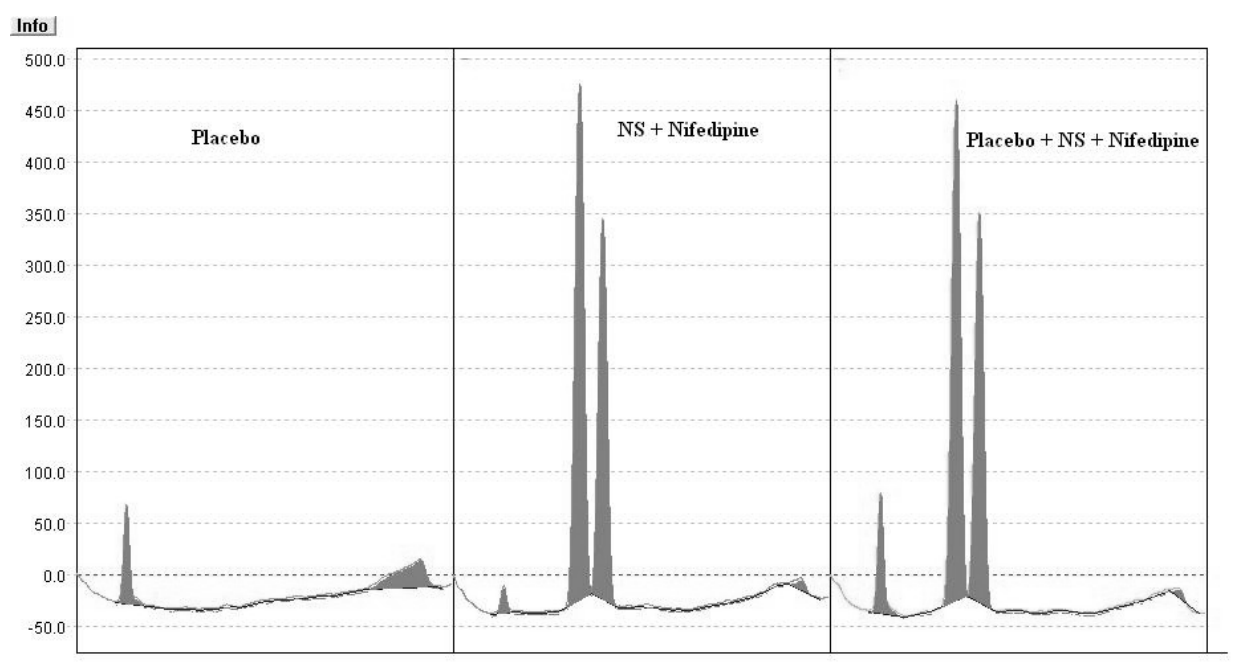

Figure 1. Specificity of analytical method.

The $\mathrm{R}_{\mathrm{f}}(0.36)$ where NS eluted was free of interferences in all of the drug free placebo and internal standard. Although an initial peak at the sampling point was obtained which might be because of uneluted placebo portion since such peaks were not seen in spectra for standard sample solutions. It was also observed that presence of such peaks did not limit the linearity of method.

\section{Accuracy and precision}

Intra-day and inter-day accuracy and precisions are summarized in Table 2. Two concentrations (low, $400 \mathrm{ng}$ and high, $2400 \mathrm{ng}$ ) were selected for the study. The intra-day and inter-day accuracy was equal to or more than 98.4 and $99.5 \%$ for spiked placebo sample and standard NS samples. The intra and inter-day precision ranged from 4.7 for the all samples studied. Reproducibility was checked by measuring the precision of the method in another laboratory on a different instrument with analysis performed by another person. Both intra-day and inter-day precision were determined and found to be less than $3.20 \%$ with no significant differences between values for intra-day and inter-day precision. The small value of RSD obtained shows that determination of NS in placebo solution is highly reproducible with the proposed procedure ${ }^{29}$ and indicates that the reproducibility of the method.

Table 2. Accuracy and precision data.

\begin{tabular}{cccccccccc}
\hline & \multicolumn{3}{c}{ Intra-day reproducibility } & & \multicolumn{4}{c}{$\begin{array}{c}\text { Inter-day } \\
\text { reproducibility }\end{array}$} \\
\hline \multirow{2}{*}{$\begin{array}{c}\text { Concentration } \\
\text { (ng per zone) }\end{array}$} & $\begin{array}{c}\text { Concentration } \\
\text { found }\end{array}$ & Accuracy & Precision & $\begin{array}{c}\text { Concentration } \\
\text { found }\end{array}$ & Accuracy & Precision \\
\cline { 2 - 11 } & mean & $\%$ & SD & $\begin{array}{c}\% \\
\text { RSD }\end{array}$ & mean & $\%$ & SD & $\%$ \\
RSD \\
\hline $\begin{array}{c}\text { Placebo } \\
50\end{array}$ & 49.85 & 99.7 & 26.01 & 2.13 & 49.76 & 99.52 & 15.19 & 2.94 \\
250 & 250.08 & 100.032 & 9.45 & 1.1 & 247 & 98.8 & 26.1 & 0.92 \\
$\begin{array}{c}\text { Standard } \\
50\end{array}$ & 49.71 & 99.42 & 24.71 & 1.96 & 48.38 & 96.76 & 13.1 & 1.07 \\
250 & 248.89 & 99.556 & 7.74 & 1.42 & 246.44 & 98.576 & 31.55 & 2.68 \\
\hline
\end{tabular}




\section{$L O D$ and $L O Q$}

The LOD is expressed as 3.3\%/slope of the calibration curve of the NS and LOQ is expressed as $10 \sigma$ /slope of the calibration curve of the NS which were found to be $4.3 \mathrm{ng} \mathrm{spot}^{-1}$ and $12.9 \mathrm{ng} \mathrm{spot}^{-1}$ respectively, which indicates the adequate sensitivity of the method.

\section{Recovery}

Extraction efficiency of the method was evaluated in the range of 400 to $2400 \mathrm{ng}$ (Table 3). Mean recovery $(n=6)$ was $100.9 \pm 0.6 \%$ for NS. The extraction efficiency is not statistically different over the range of concentration studied.

Table 3. Extraction efficiency of nisoldipine at various concentrations.

\begin{tabular}{cccc}
\hline \multirow{2}{*}{ Nisoldipine (ng/ zone) } & \multicolumn{2}{c}{ Mean area of peak } & $\begin{array}{c}\text { Extraction } \\
\text { efficiency, \% }\end{array}$ \\
\cline { 2 - 3 } & Extracted & Standard solution & 98.8 \\
400 & 378.8 & 383.2 & 99.3 \\
1200 & 651.1 & 655.3 & 100.0 \\
1600 & 847.4 & 846.7 & 99.8 \\
2000 & 1059.7 & 1061.7 & 99.9 \\
2400 & 1210.7 & 1211.0 & 100.2 \\
\hline
\end{tabular}

\section{Conclusion}

An easy, simple and validated method for NS is developed. This method has low detection limits, high recovery, wide dynamic range with acceptable precision and a simplest extraction procedure when compared with other methods hence method is found to be suitable to determine the NS in bulk and pharmaceutical products.

\section{Acknowledgment}

We acknowledge all scientists who have worked on analysis of Nisoldipine and created a platform for its thin layer chromatographic determination.

\section{References}

1. Agbaba D, Vucicevic K and Marinkovic V, Chromatographia,, 2004, 60, 223.

2. Fossheim R, Joslyn A, Solo AJ, Luchowski E, Rutledge A and Triggle D J, J Med Chem., 1988, 31, 300.

3. Kapor A, Ribar B, Tomic Z, Marinkovic V and Vladimirov S, Kristalna I, Acta Periodica Technologica, 2000, 31, 693.

4. Mielcarek J, Grobelny P and Szamburska P, Methods Find Exp Clin Pharmacol., 2005, 27, 167

5. Dogrucol-Ak D, Gokoren N and Tuncel M A, Anal Lett., 1998, 31, 105.

6. Likussar W, Michelitsch A and Schubert-Zsilavecz M, Monatsh Chem., 1994, 125, 509.

7. Mariniec B and Brzeska A, Chem Anal., 1999, 44, 849.

8. Zhang Z, Tian Y, Ni L and Li J, J Chromatogr Sci., 2004, 42, 501.

9. Wu H, Zhang L and Yuan Z, Chin J Pharm Anal., 2006, 26, 799.

10. Ohkubo T, Uno T and Sugawara K, J Chromatogr A., 1994, 659, 467.

11. Chankvetadze B, Chankvetadze L, Sidamonidze S, Yashima E and Okamoto Y, $J$ Pharm Biomed Anal., 1995, 13, 695.

12. Marinkovic V, Agbaba D, Karljikovic-Rajic K, Comor J and Zivanov-Stakic D, Farmaco, 2000, 55, 128. 
13. Vetuschic C, Ragno G, Veronico M, Risoli A and Ginnandrea A, Anal Lett., 2002, 35, 1327 .

14. Alvarez-Lueje L, Naranjo L J, Nunez- Vergara J A and Squella J, J Pharm Biomed Anal., 1998, 16, 853.

15. Alvarez-Lueje L, Sturm J, Squella J A and Nunez-Vergara L J, J Pharm Biomed Anal., 2002, 28, 887.

16. Marinkovic V, Agbaba D, Karljikovic-Rajic K, Vladimirov S and Nedeljkovic J, $J$ Pharm Biomed Anal., 2003, 32, 929.

17. Van Harten J, Lodewijsk M T, Guyt-Schiten J W, Van-Brummelen P and Breimer D D, J Chromatogr Biomed Appl., 1987, 423, 327.

18. Barbato F, Grumetto L and Morrica P, Farmaco, 1994, 49, 461.

19. Heinig R, Muschalek V and Ahr G, J Chromatogr B., 1994, 655, 286.

20. Snedden W, Fernandez P G, Galway B A and Kim B K, Clin Invest Med., 1984, 7, 173.

21. Grundy J S, Kherani R and Foster R T, J Chromatogr B Biomed Appl., 1994, 654, 146.

22. Zimmer D and Muschalek V, J Chromatogr A ., 1994, 666, 241.

23. Soons P A, Roosemalen M C and Breimer D D,. J Chromatogr B., 1990, 528, 343.

24. Wonku K, Anal Sci., 2006, 22, 1597.

25. Huang Y, Shao-Xuan F U and Yun-Shan L, Acta Pharmcol Sin., 1990, 11, 484.

26. Szepesi G and Nyiredy S, J Pharm Biomed Anal., 1992, 10, 1007.

27. Frenczi-Fodor K, Ve'gh Z and Renger B, TrAC, 2006, 25, 778.

28. Sherma J, Planar Chromatography Anal Chem., 2004, 76, 3251.

29. Jamshidi A and Nateghi A R, Chromatographia, 2007, 65, 763. 


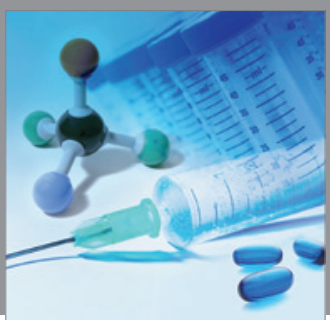

International Journal of

Medicinal Chemistry

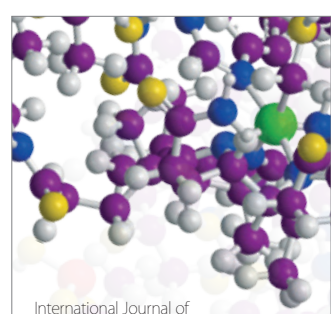

Carbohydrate Chemistry

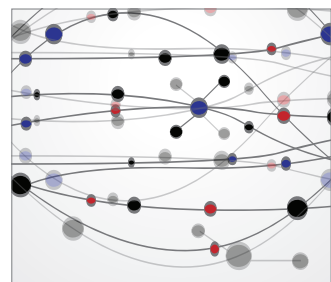

The Scientific World Journal
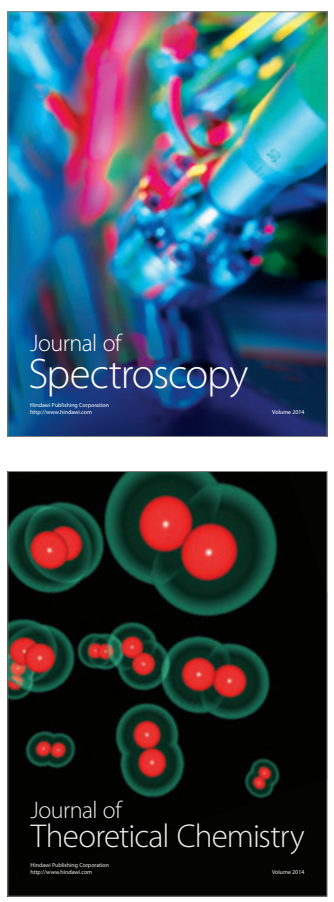
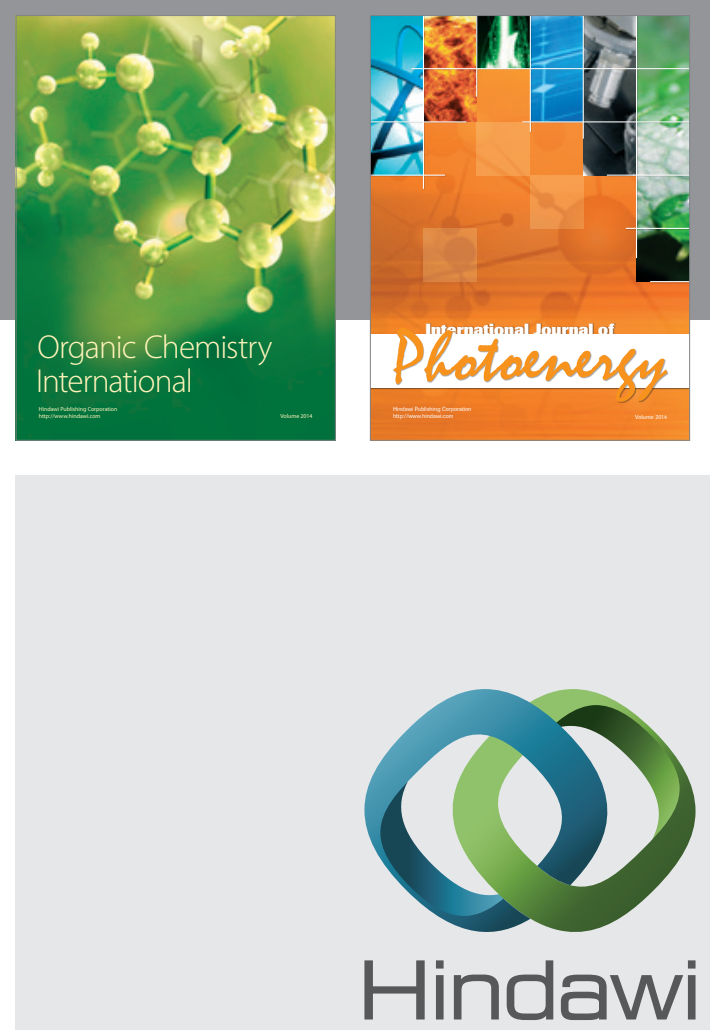

Submit your manuscripts at

http://www.hindawi.com
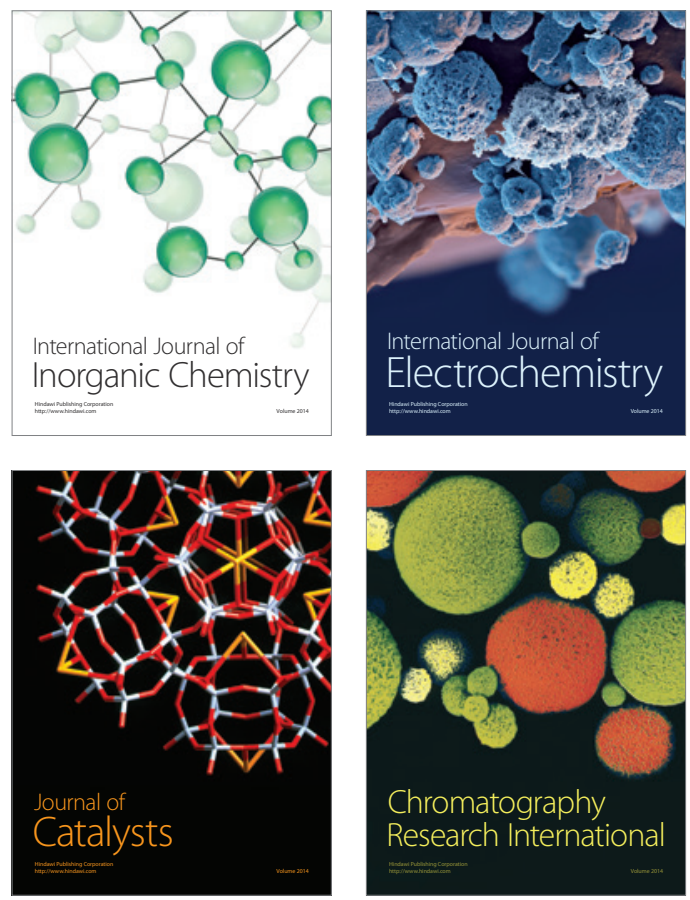
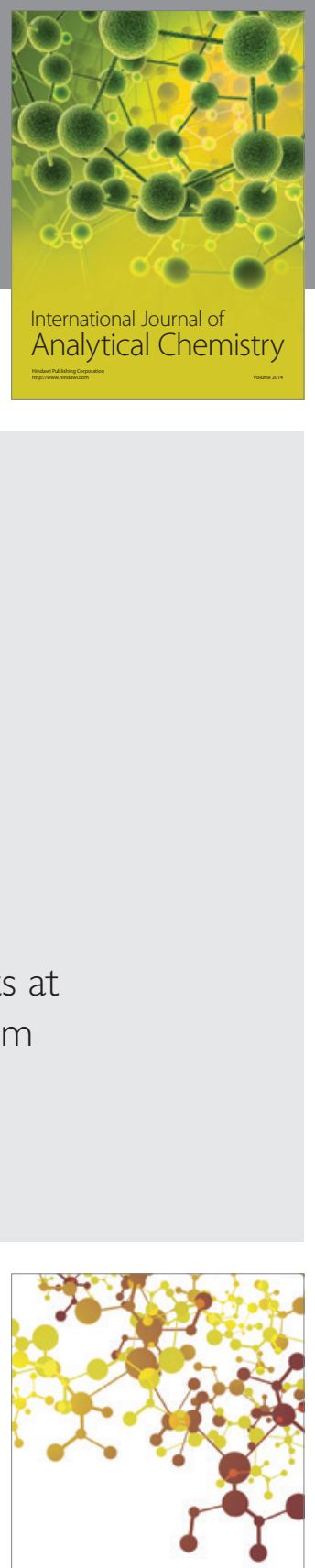

Journal of

Applied Chemistry
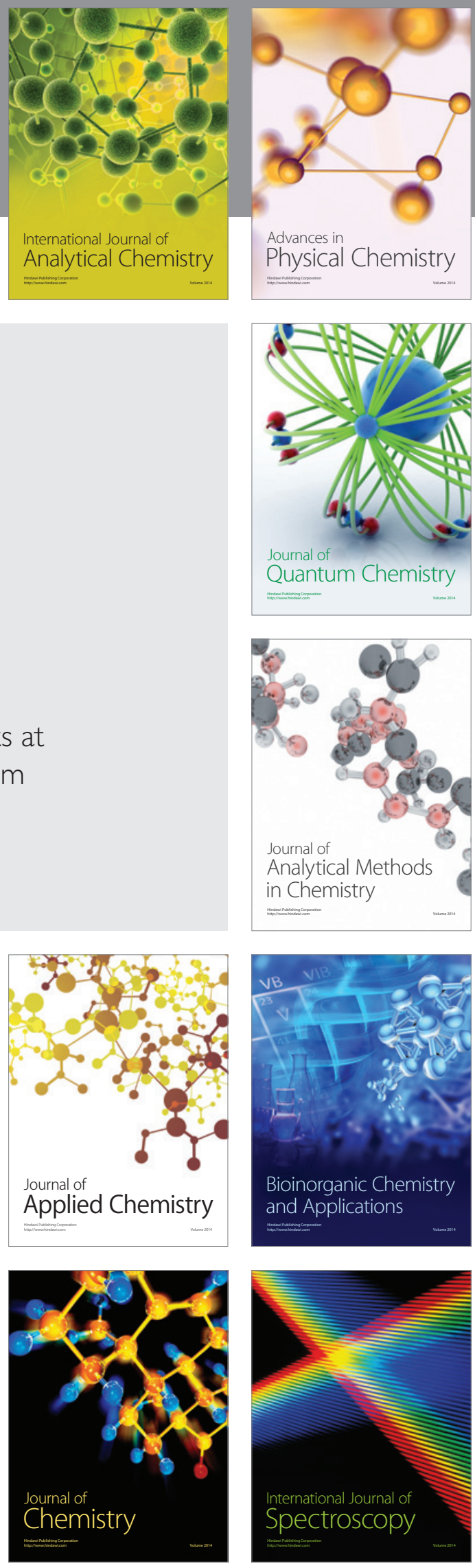